Biomedical

Research \& Therapy

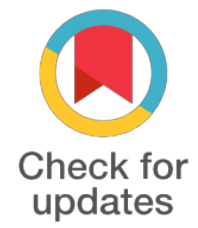

*For correspondence:

fionamac11@yahoo.com

Competing interests: The authors declare that no competing interests exist.

Received: 2017-07-14 Accepted: 2017-08-04 Published: 2017-09-05

Copyright The Author(s) 2017. This article is published with open access by BioMedPress (BMP).

This article is distributed under the terms of the Creative Commons Attribution License (CC-BY 4.0) which permits any use, distribution, and reproduction in any medium, provided the original author(s) and the source are credited.

POSTER

\title{
Telomerase activity, telomere length and P53 mutation detection on cellular senescence of Human Amnion Mesenchymal Stem Cells (HAMCs)
}

\author{
Fiona Macniesia Thomas, Vijay Kumar, Siti Fatimah Simat, Helen \\ Benedict Lasimbang
}

Biotechnology Research Institute Universiti Malaysia Sabah

\begin{abstract}
A fundamental understanding of senescence in human amnion mesenchymal stem cells (HAMCs) is crucial for its application in cellular therapy. Previous findings strongly support that HAMCs undergoes cellular senescence after long term in-vitro culture, with evidence of significant morphological changes and the presence of the senescent associated $\beta$-galactosidase (SA- $\beta$-Gal) marker. The telomere length and the telomerase activity have been linked with cellular aging and they are important in regulating cell proliferation. In addition, p53 gene has been associated with cell senescence. The aim of this study was to investigate the telomerase activity, telomere length in senescent HAMCs, and to detect p53 mutations in these cells. Samples were obtained from amnion placenta and then cultured for long term. Prolong-cultured HAMCs was isolated at passages 5,10 and 15 and then analysed via telomeric repeat amplification protocol (TRAP), telomere length assay and p53 mutation detection assay. The results showed that after long term culture of HAMCs, there was a decrease in telomere length and telomerase activity from passages 5, 10 to 15. Telomerase controls the telomere's length which maintains the cells proliferation. The decrease of telomere length and telomerase activity may suggest that the proliferation of HAMCs has slowed down due to HAMCs entering senescence after long term culture. P53 mutation detection study indicated that HAMCs at all passage did not have altered sequences. Thus, the cells did not undergo uncontrollable replication due to the effect of long-term culture. Further studies on senescence in HAMCs will be assessed by investigating the expression level of p53, p21, p16, pRB and GADD 45 genes in long term culture of HAMCs via RT-qPCR. The findings will help us understand the associations between gene expressions and the process of senescence.
\end{abstract}

\section{Keywords}

Stem cells, senescence, telomerase, p53

Funding

References 